\title{
Study on Wear of Scraper Conveyor Chute
}

\author{
Hongwei Chen ${ }^{1, a}$, Rongjie Wang ${ }^{2, b}$ \\ ${ }^{1}$ Department of Mechanical and Electrical Engineering, Longyan University, Longyan ,Fujian, \\ 364012, China \\ ${ }^{2}$ Department of Mechanical and Electrical Engineering, Longyan University, Longyan ,Fujian, \\ 364012, China
}

a13626028318@139.com, ${ }^{\mathrm{b}} 13859506650 @ 139 . c o m$

Keywords: scraper conveyor; chute; friction; wear;

\begin{abstract}
The wear of the middle trough of coal mine scraper conveyor, is a common fault of scraper conveyor. Starting with the causes of wear by analyzing the structure and the working condition of the chute, it indicates that the friction is the main cause of the chute wear, and abrasive wear, adhesive wear, fatigue wear and corrosion wear are the main forms of chute failure. The use of new materials and strengthening the maintenance can prevent the chute wear of scraper conveyor and improve service life.
\end{abstract}

\section{Introduction}

Because of the high structural strength, the large transport capacity, the bending capacity and moving easily, the scraper conveyer is widely used in the production of coal mine. Chute is one of the main components of scraper conveyor and the middle groove is not only the principal part of the chute, but also the main energy consumption and wear part, whose abrasion and corrosion failure could lead to the jump chain clamping phenomenon and causing chain scission, motor overload and even burning motor, resulting in serious economic losses. This paper analyses the wear condition of the middle trough of SGW-44 type scraper conveyor, and put forward the measures of improvement.

\section{The composition and structure of the chute}

The chute of scraper conveyor is used for bearing the body and as a track for shearer. Chute has regulating tank, connecting tank and mostly, the middle groove. The middle groove is welded by channel steel and median plate, as shown in figure 1. The upper grooves are bearing grooves for the shipment of materials, and the lower grooves have two type: one has the openings at the bottom and the other hasn't, which are all used for the return and back of the scraper chain. The types of the middle groove are single type, edge double chain type and double chain type. The SGW-44 type uses edge double chain and its sectional form of channel steel is the type M.
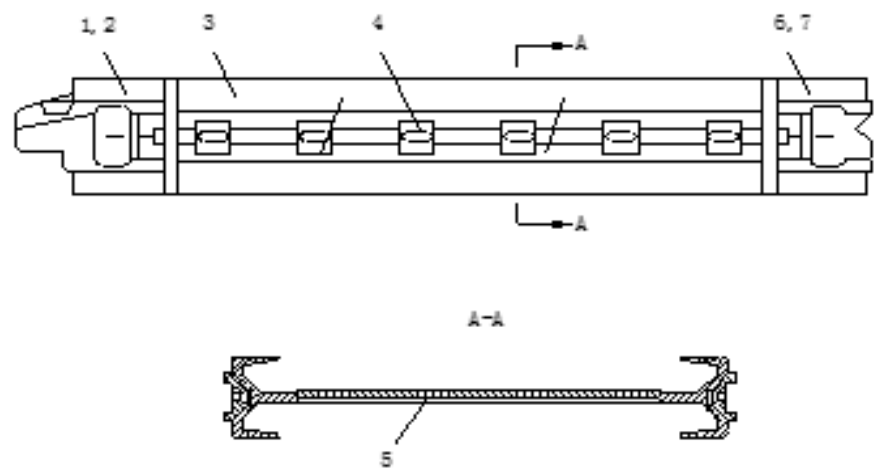

Fig.1 The middle groove

1, 2--high manganese steel protruding side; 3-channel steel; 4-bearing;

5-mediun plate; 6, 7-high manganese steel concaving side. 


\section{Chute condition and main fault}

The working principle is that using the infinite loop of the scraper chain around the nose sprocket and the tail sprocket as traction mechanism, using the chute as bearing mechanism, when the motor is started, the hydraulic coupler and the speed reducer drive the chain wheel to rotate, thereby driving the scraper chain into continuous operation, then, the cargo installed in the chute will be transported to the head from the tail, as shown in figure 2.

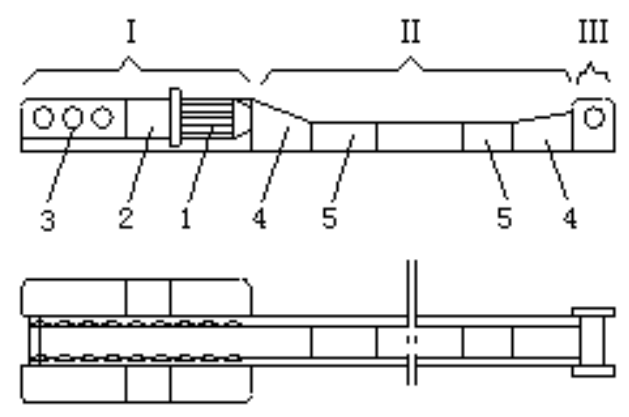

Fig.2 Scraper conveyor structure diagram

1-Motor; 2- Hydraulic couplers; 3-Reducer; 4-Transitional chute; 5-middle groove;

I -chain-drive section; II -rear part; III-middle part.

SGW-44 type scraper conveyor chute material for 16Mn hot-rolled plate, at work due to compression, tension, bending, by shock, friction, vibration, corrosion and other effects, therefore, wear is the main failure.

\section{Cause analysis}

The surface where the two are in contact or in relative motion, are not to have friction, a friction wear occurs. Therefore, the friction material chute and transportation are the main reasons to cause the chute abrasion. Many wear type, SGW-44 type scraper conveyor chute wear mainly in the form of:

Abrasive wear. Abrasive wear generally refers to hard abrasive or projection machine parts in contact with each other in the process of the surface, the surface material of a kind of phenomenon of loss or process. Scraper chain surface along the chute in runtime, the convex surface body, chain and chain chute between hard particles wear of the chute are abrasive wear, hardness higher link and soft chute slide correspondingly, microcosmic performance for a lot of asperity contact, during which the abrasive is coal, gangue and metal particles and corrosion the product, as the main abrasive or coal and gangue mineral is hard, by scanning electron microscope, the chute chain channel morphology preliminary think: in addition to abrasive cause chute on chip form outside the main mechanism of spalling, plowing the plastic deformation. Clip in the chain and between the sheets in the coal and gangue, also can produce micro cutting and stripping of the chute.

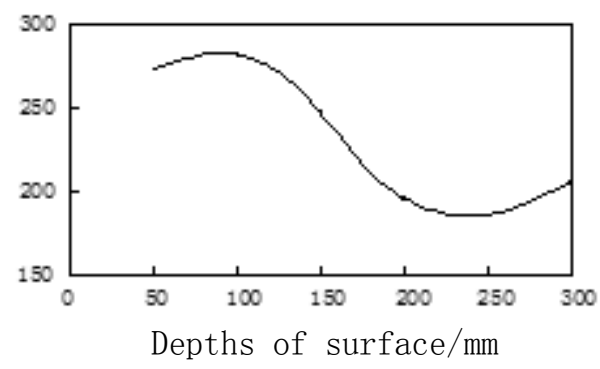

Fig.3 Changes of the hardness along with the depths of surface

According to the classification of abrasive wear, that is three body abrasive wear, abrasive only about $10 \%$ of the time is generated on the surface of the sliding, wear. Coal and gangue clip relative 
movement between the chute and link, belonging to three body abrasion. Abrasive to squeeze squeeze metal in groove on both sides and the front, when the link and abrasive surface of each through the plate a, the shear strain is accumulated at a time, so the wear surface under the place of severe plastic deformation. Plastic deformation by fracture limit, i.e. when meet material fracture criterion by surface peeling, chute end head chain plastic deformation layer grain sliding direction of skew, the distorted layer from the wear surface hardness with depth size changes. As shown in figure 3. The furrow on both sides of the metal by repeatedly pressing the continuous rolling and low cycle fatigue peeling backward model consists of 4 stages. (1): while the furrows occur due to abrasive or chute role; (2) second rolling or furrows; (3) repeated rolling ploughing and crack formation; (4) crack produce spalling. As shown in figure 4.

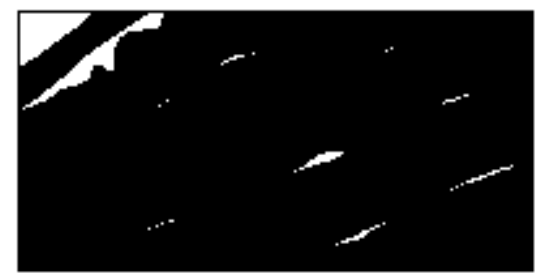

Fig.4 Abrasive wear furrows and chip morphology

$16 \mathrm{Mn}$ steel middle groove $\times 400$

Adhesive wear. Adhesive wear is actually in contact with each other on the surface of the micro convex forming adhesive contacts and contact fault constantly body caused friction surface damage and formation process of debris. Scraper chain and chute contact, see only the asperity contact from microscopic, so the link bearing after effect in a very high pressure micro convex body. If more than the limit yield stress, plastic deformation occurs, until the real contact area increases with the external load to date. Although the link and the chute surface contaminants, such as coal, oxidation film, but the relative moving interface is sufficient to enable the contaminated membrane contact point disappear, the asperity contact points on the occurrence of "cold" phenomenon, and links to continue movement made the chain channel contact produces cut and formed new connection point, adhesive wear this the formation of chain road.

Corrosion wear. Corrosion and wear a wear and corrosion wear is also playing a role. The underground mine water containing oxygen, sulfur four ions and dissolved oxygen and free carbon dioxide, chemical reaction with the friction pair surface, resulting in corrosion. Observations confirm the corrosion pit corrosion is due to the chain and adhesive wear after the chute. Layer or corrosion pit corrosion caused by grain boundary crack corrosion, to flaking in the absence of friction.

Contact fatigue wear. Machine parts in rolling and sliding or rolling composite action under the contact fatigue wear, mainly due to the long-term effects of alternating contact stress and surface fatigue spalling phenomena caused by the. Coal gangue on the surface will produce different shades of pit and large area in the long run when peeling chute.

\section{Summary}

The material of the chute of SGW-44 type scraper conveyor is made of hot-rolled plates of $16 \mathrm{Mn}$ steel. The main wear of the chute are abrasive wear, adhesive wear, fatigue wear and corrosion wear. The wear resistance of $16 \mathrm{Mn}$ steel can not meet the requirements of the middle groove. In research design, it may be taken into consideration to use modified MC as a new material, for modified MC has anti-corrosion, abrasion resistance and light quality. Also, using 40Mn2 steel cold rolling plate instead of $16 \mathrm{Mn}$ hot-rolled plate to produce scraper conveyor middle groove could result in no adhesive wear, less abrasive wear and its wear resistance improved obviously. In addition, strengthening maintenance and improving wear resistance are the two methods that turn out to be correct after the practice in coal mining. 


\section{References}

[1] Cheng Jushan et al. Mining machine [M]. Xuzhou: China University of Mining and Technology press, 1997.5

[2] Shao Hesheng. Friction and wear [M]. Beijing: China Coal Industry Publishing House, 1992.9

[3] Cola Gailes Ki. Friction and wear and lubrication Handbook [M]. Beijing: Mechanical Industry Press, 1982.10

[4] Liu Bai. Coal mine scraper conveyor $16 M n$ steel middle groove wear failure analysis[J]. Special steel, 2003 (11):p.43-44

[5] Liang Lixun. The scraper conveyer in the development of modified MC nylon [J] .central groove. The engineering plastics application, 2002 (2),p.36-38

[6] Pei Zhongai,Wang Rongjie. Invalidation analysis and improvement of Scraper Conveyor Chute [J].Coal mine machinery, 2007 (3):p.23-27

[7].Wang Rongjie, Chen Hongwei. Analysis and improvement on drum fracturing of the Belt Conveyor Roller [J]. Coal mine machinery, 2005 (11):p.42-46 